\title{
An Experiential Learning Approach to Develop Leadership Competencies in Engineering and Technology Students
}

\section{Dr. Gregg Morris Warnick, Brigham Young University}

Gregg M. Warnick is the Director of the Weidman Center for Global Leadership and Associate Teaching Professor of Engineering Leadership within the Ira A. Fulton College of Engineering and Technology at Brigham Young University (BYU). The center provides oversight for leadership development and international activities within the college and he works actively with students, faculty and staff to promote and develop increased capabilities in global competence and leadership. His research and teaching interests include developing global agility, globalization, leadership, project management, ethics, and manufacturing processes. Gregg has lived in numerous locations within the USA and Europe and has worked in many places including North America, South America, Europe, Asia, and Africa. Prior to joining BYU, Gregg worked for Becton Dickinson, a Global Medical Technology fortune 500 Company. In this capacity he worked as a product development engineer, quality engineer, technical lead, business leader and program/project manager managing many different global projects. Gregg received his $\mathrm{PhD}$ in Educational Leadership and Higher Education from the University of Nebraska-Lincoln with a Master of Technology Management degree and a BS in Manufacturing Engineering Technology, from Brigham Young University. Gregg also does consulting in project management and leadership working with IPS Learning and Stanford University where he provides training for fortune 500 companies throughout the world.

Joshua Schmidt, Brigham Young University

Prof. Anton E Bowden, Brigham Young University

Anton E. Bowden is an Associate Professor in the Department of Mechanical Engineering at Brigham Young University. He holds a B.S. in Mechanical Engineering from Utah State University and a Ph.D. in Bioengineering from University of Utah. He received a CAREER award from the National Science Foundation for his work investigating the role of ligaments as related to biomechanics of the lumbar spine. He is actively involved in the development and teaching of the integrated leadership, ethics, and globalization curriculum at BYU and was recently appointed Weidman Professor in Leadership. 


\title{
An Experiential Learning Approach to Develop Leadership Competencies in Engineering and Technology Students
}

\begin{abstract}
There is a shift occurring among many engineering and technology programs throughout the world in the mode of instruction for leadership development in their students. Where it was once common to have a few seminars on leadership or maybe even a typical lecture-based course, there is a growing trend to provide experiential learning (hands-on) leadership experiences for students that better prepare them for success within their careers.

Building upon the experiences of other engineering and technology programs focused on leadership development as well as that of our own at Brigham Young University (BYU), this paper presents the use of an experiential learning approach in the development of leadership competencies among engineering and technology students. It analyzes varying approaches used by other universities. The paper describes some of the challenges of transitioning from a typical lecture-based approach to an experiential learning approach while describing associated benefits related to engineering and technology student leadership outcomes.
\end{abstract}

\section{Introduction}

It is increasingly apparent that today's engineering challenges require a higher order of thinking. The Accreditation Board for Engineering and Technology (ABET) states that engineering programs must demonstrate that their baccalaureate students attain certain outcomes for graduation. A set of 11 student outcomes ${ }^{1}$ are described in General Criterion 3 that can be divided into two primary categories: five "hard" technical skills and a second set of six "professional" or "soft" skills ${ }^{2}$ as indicated in Table 1 below.

Table 1 - ABET General Criterion 3. Student Outcomes

\begin{tabular}{|c|l|}
\hline Criterion & Professional Skills from ABET General Criterion 3 \\
\hline $3 \mathrm{~d}$ & An ability to function on multidisciplinary teams \\
\hline $3 \mathrm{f}$ & An understanding of professional and ethical responsibility \\
\hline $3 \mathrm{~g}$ & An ability to communicate effectively \\
\hline $3 \mathrm{~h}$ & $\begin{array}{l}\text { The broad education necessary to understand the impact of engineering solutions in } \\
\text { a global, economic, environmental, and societal context }\end{array}$ \\
\hline $3 \mathrm{i}$ & A recognition of the need for, and an ability to engage in life-long learning \\
\hline $3 \mathrm{j}$ & A knowledge of contemporary issues \\
\hline
\end{tabular}

ABET outcomes clearly demonstrate a focus on core technical skills as well as other skills including leadership as indicated in Table 1.

Preparing engineering graduates with the leadership skills necessary for real-world problems by shifting to experiential learning is no small task. Engineering programs are already overloaded with credits, content, and other demands. In academics, there is a often a struggle between providing technical content and what many refer to as "soft or profession" skills such as 
leadership. Often the winner is technical content and professional skill development is relegated to a few seminars or incorporated as a few lectures within a senior design course. Since leadership development is a process that requires not only knowledge, but also particularly time and experience it is imperative that the process for development begin as early as possible.

This paper will discuss the importance of leadership development in engineers and the need for a shift toward experiential learning and what doing so would entail. We also present a brief outline of what other engineering and technology programs are doing to meet this need as well as experiences from our own university. In addition, this paper addresses the challenges and benefits of engineering and technology programs shifting to experiential learning.

\section{The Need for Experiential Leadership Education}

It is not uncommon to hear that "an engineer is hired for his or her technical skills, fired for poor people skills, and promoted for leadership and management skills." 3 Due to the phenomenal changes in communication and transportation technology coupled with economic factors that have made international trade virtually ubiquitous, engineers are now required to work in a global environment. The global workplace has placed increased demands on engineers, specifically in the realm of the professional skills. Employers now seek graduates who not only demonstrate strong technical ability, but also have developed leadership skills necessary to succeed in industry ${ }^{4,5,6,7,8}$. These skills include:

- Self awareness

- Integrity and ethical decision making

- Interpersonal skills

- Communication

- Problem solving

- Project management

- Teamwork and team development

- Conflict resolution

- Planning, organizing and strategy formulation

- Coaching and mentoring

- Time management and prioritization

- Cultural awareness

- Global Agility

Russell and Yao (1996) argued that engineers must be taught leadership skills in order to succeed in the workplace. They noted that engineers must be able to communicate a presentation to the level of understanding of the readers or listeners ${ }^{3}$. This skill requires the development of communication skills and interpersonal skills. In addition, engineers are often required to work in cross-discipline teams ${ }^{3,9}$. Working in such teams warrants the need for the skills mentioned above.

In order to meet the demand for students who are better prepared for leadership situations, there has been a shift occurring among many engineering and technology programs towards experiential learning. Traditional leadership education consisted of seminars and lecture-based courses to instil knowledge of leadership principles and concepts in the minds of students. 
Although these traditional techniques are effective at initiating lower levels of learning $\operatorname{cognition}^{10}$, it has been shown that lecture-based learning of leadership topics is not as effective as experiential-based learning for developing higher levels of learning cognition. Experiential learning specifically requires analysis and application of concepts and principles in real-life or simulated real-life problems ${ }^{4,5,11,12,13}$.

Experiential learning is commonly referred to as learning by doing and typically involves discovery and exploration with a focus on learning through experience. Extensive research has been done regarding the need to shift toward experiential learning. Kolb originally identified four main components of experiential learning as shown in Figure 1 and also described below: ${ }^{11}$

1. Concrete Experience - The key to learning is active involvement. Kolb's research indicates that an individual can't simply read, watch or listen but to learn effectively they must do.

2. Reflective Observation - Reflection on the new experience while focusing on any inconsistencies between experience and understanding.

3. Abstract Conceptualization - Reflection gives rise to a new idea or a modification of an existing abstract concept.

4. Active Experimentation - The learner applies them to the world around them to see results.
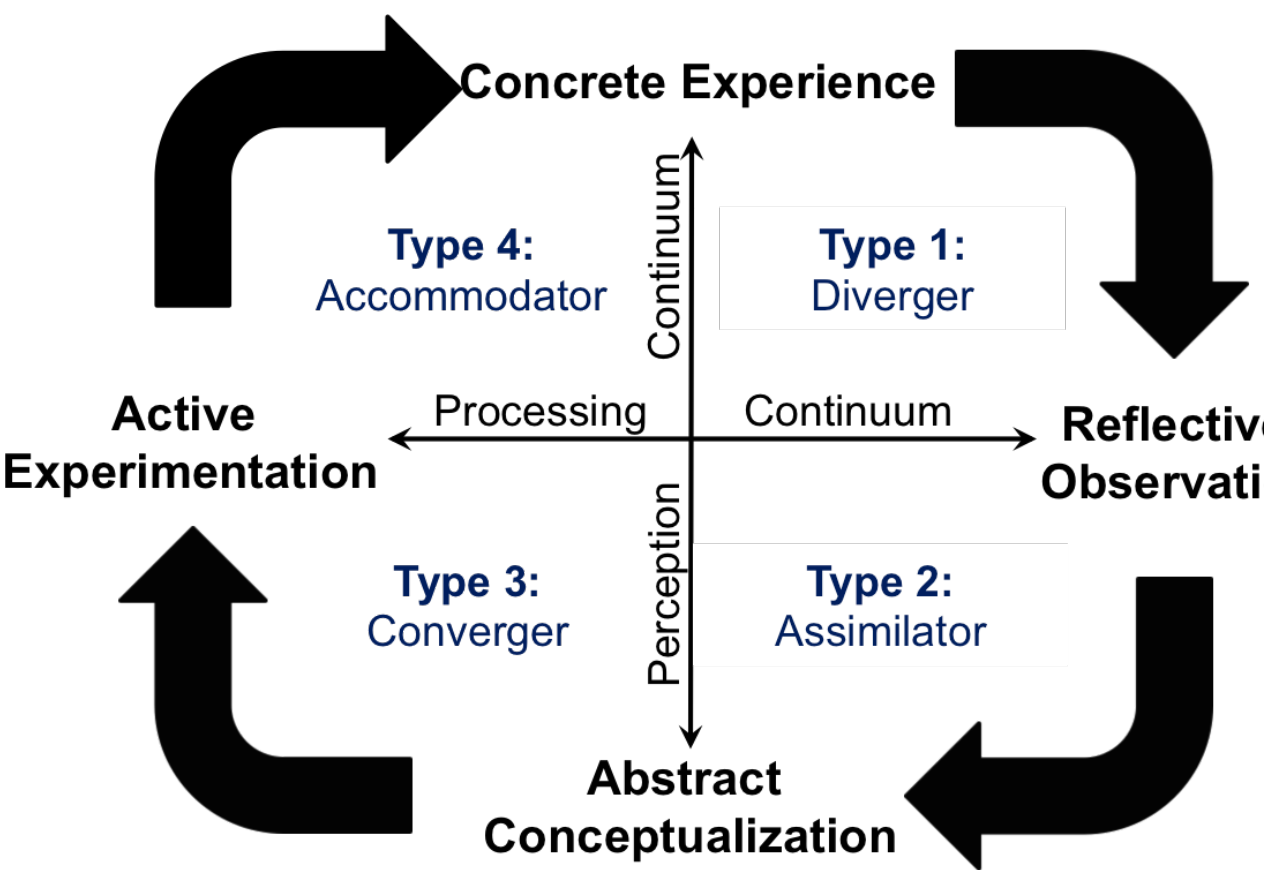

Figure 1 - Adapted from Kolb's Experiential Learning Cycle $\left(\right.$ Kolb, 1984) ${ }^{11}$

Experiential learning is not a new approach within engineering education as it is a common method utilized within technical courses utilizing laboratory experiences to provide students "hands on learning". However when it comes to developing leadership within engineers, too often a lecture-based approach is utilized. Most college instructors teach through lectures because that is the way they were taught and where they are most comfortable or they just have not learned otherwise ${ }^{14}$. While there is certainly a place for good lectures in effective teaching, 
faculty need to involve students in discussions, team-based activities, laboratory experiences, peer-led learning, and hands-on participation to maximize learning outcomes.

While the Kolb Experiential learning model is a good standard for experience-based learning, it is difficult for instructors to implement without further explanation. With more research having been done on experiential learning, several elements of implementation stand out:

1. Leadership education should be implemented early on in an academic career - Early implementation gives more time for students to develop the leadership skills desired. Because the skills sometimes take time to instil, the more time that is given the better ${ }^{8,15}$.

2. Leadership education should be done in teams - Today's engineers no longer work alone, but work in teams with personnel from various fields of study. Teamwork is an essential characteristic for prospective engineering leaders to build ${ }^{4,13,16,17}$.

3. Active involvement of students allows them to take responsibility for their own learning and the learning of others - It has been shown that when students are in charge of their own learning and the learning of others that they learn more. In addition, allowing students to be in charge of their own learning prepares them for a life of learning ${ }^{12,15,20}$.

4. Emphasis should be placed on skill building instead of knowledge acquisition - Although knowledge acquisition is important, focusing on skill-building actually does more to help students understand the concepts and principles of leadership than does focusing on the knowledge $^{17,18}$.

5. Gradually withdraw support, as students are more comfortable-Removing support allows students to learn from their own experiences instead of the experience of others. Instructors should begin with activities that are comfortable for the students in order for connections to be made. In addition, a sudden change in learning style may be too difficult for students; thus it is important to gradually lead them ${ }^{4,13}$.

6. Debriefing is the most critical part of experiential learning - The debriefing allows students the opportunity to learn from their mistakes and reflect on what they have done and learned. Without reflection, students may become discouraged or make mistakes without learning from them. Reflections and debriefing can be done through discussion, writing, or in case studies ${ }^{19,20,21}$.

Efforts to develop leadership in engineering students are likely to be enhanced by incorporating the implementation elements described above.

\section{Current Efforts in Engineering Leadership Education}

There are two types of engineering leadership development strategies utilized by pioneering universities. The first and more popular strategy is to create a supplementary program to the engineering curriculum where students are able to participate in leadership courses or programs 
in addition to their required curriculum. The second and more difficult approach is to implement experiential leadership education into the curriculum including required engineering courses.

Mentioned here are a few programs that have adjusted to experiential engineering leadership education. These universities have been forerunners in the change towards experiential leadership education.

The Massachusetts Institute of Technology (MIT) Gordon Engineering Leadership Program is one of the better-known engineering educational leadership development programs. The Gordon Engineering Leadership Program (GEL) ${ }^{22}$ integrates experiential-based leadership learning with core engineering courses.

- Students must apply after going through a preparatory program or after receiving engineering experience from a qualified project. The GEL incorporates leadership instruction in addition to normal engineering courses.

- UPOP: Students start their sophomore year. They start with the Undergraduate Practice Opportunities Program (UPOP). Those in the program have personalized coaching, are given a summer internship, participate in post-internship reflective activities, and build basic interpersonal skills

- GEL Year One: Juniors or seniors who have completed the UPOP or who have qualified through experience on an engineering project can apply for the first year of the program. Students are taught by experiential learning through case studies and interactive courses, and weekly Engineering Leadership Labs, followed by guided reflection of their experiences.

- GEL Year Two: Only students who have completed Year One of the program are allowed to apply for the second year. Students are given leadership responsibilities in class, labs, and in a mentored experience called InternshipPlus

In addition, GEL offers its resources for professors to use in their core engineering courses. MIT's GEL program is highly selective allowing very few students to participate. Although effective, the selectivity does not provide an opportunity for all students at MIT to learn the leadership skills developed through the program.

Northeastern has a Gordon Engineering Leadership (GEL) program very similar to MIT's except it is primarily focused at the graduate level. An undergraduate program is also provided which is self-directed. Experiential learning is highly stressed at Northeastern. Students gain important engineering leadership skills through hands-on projects and service-learning projects. Students are also very strongly advised to complete cooperative educational experiences. All GEL program requirements are completed over the course of one calendar year and are in addition to core graduate engineering requirements.

- Students take two graduate-level courses (Engineering Leadership and Scientific Foundations of Engineering)

- Experiential learning through working with industry partners and participation in a challenge project.

- Supplemental leadership development activities 
If all requirements are completed, students can receive a certificate on their transcript. In addition to the formal programs, Northeastern uses experiential learning in its core courses. Co-operative Education is highly stressed as well as hands-on projects and service-learning projects.

Rice University established the Rice Center for Engineering Leadership in 2010 and runs a fouryear certificate program designed to give motivated students the opportunity to study leadership and engage in a rigorous learning experience. Program requirements include the following ${ }^{23}$ :

- 10 hours of leadership coursework or 16 hours for the advanced certificate

- Leadership development experiences - practical application of leadership skills in an engineering project or student organization

- Internships - 1 professional internship for the certificate or 2 professional internships for the advanced certificate. Internships provide students the opportunity to practice their leadership development.

- Leadership development plan - Understand personal leadership capabilities, document lessons learned, and develop a plan for leadership development.

- Engineering leadership portfolio - Used to synthesize leadership related learning experiences.

- Final Leadership Presentation - Summary of highlights and takeaways that have shaped students view of leadership.

Rice allows anyone to complete the requirements and receive the certificate at graduation, however the courses are not integrated into the required engineering core.

Penn State University (PSU) has moved toward experiential learning through a minor. Penn State believes that a hands-on approach is most successful for leadership education and thus implements these methods in their teaching. The Engineering Leadership Development Minor ${ }^{24}$ seeks to provide opportunities for students to work with peers at Penn State and internationally. In order to receive the minor, 18 hours of coursework and a leadership capstone are required. All courses include labs where leadership experiences are simulated. Like MIT's GEL program, Penn State students must apply for the minor. This selective process will exclude students and possibly deter some from applying.

\section{The Brigham Young University Experience with Experiential Learning}

Beginning in 2005, Brigham Young University's Ira A. Fulton College of Engineering and Technology began an initiative to integrate leadership within the engineering curriculum. These efforts have resulted in a structured experience that provides graduates with proficiency in leadership knowledge and skills. Starting with the freshmen year students are encouraged to become involved in extracurricular activities including college and university-sponsored clubs to gain hands-on leadership opportunities. In addition, all freshmen participate in a new student leadership seminar. The Weidman Center for Global Leadership sponsors a Leadership Lecture Series three times each semester which provides an opportunity for all students, faculty and staff to learn from respected industry leaders and gain insights into leadership principles.

During their sophomore year students participate in the Foundations of Global Leadership course. The course was initially optional but now is required for all engineering and technology 
students while having the added benefit of fulfilling a general education requirement. Significant efforts are also made to encourage students to participate in the many study abroad opportunities offered within the college to gain practical leadership skills within an international environment. During the junior year, students participate in core curriculum courses with a focus on teambased projects, faculty mentoring and undergraduate research experiences. Internships are recognized as an important practical method for leadership development and the college provides significant support to students seeking practical work experience with sponsoring companies both domestically internationally. During the senior year students participate in culminating practiced leadership experiences in senior design/capstone project courses. Figure 2 illustrates the integrated leadership development approach utilized.

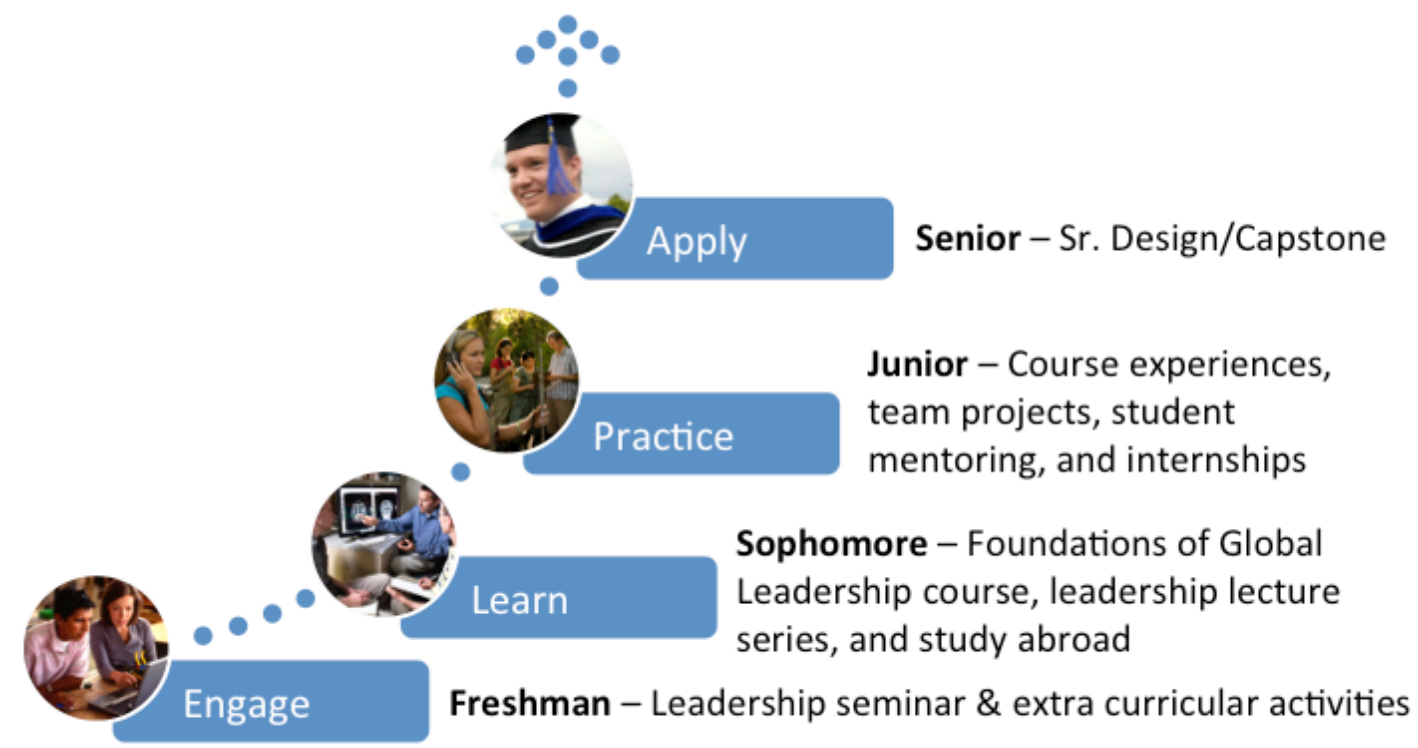

Figure 2 - Leadership Development at Brigham Young University

The transition to experiential learning has been a gradual process. The Foundations of Global Leadership course has evolved in recent years from a more typical lecture-based course to an experiential leadership development course. In recent years the course has included many positive experiential learning activities including: student discussions, student-led activities, team-based projects, and opportunities for effective feedback. Even with these improvements the course has had its challenges including an average class size of 80 students in a tiered-fixed desk classroom arrangement. As a result, much of the instruction remained primarily in a lecturebased format due to class size and facility constraints.

The authors have taught the course more than ten times over the past few years and have collaborated to improve the offering each time with a focus on maximizing student learning as it applies to leadership development. Inspired by collaboration visits conducted by the authors at MIT and PSU and through research and course design efforts, particular attention was given to the identification of specific topics that would receive a maximum return from an experiential approach. Our selection criteria was based on two primary factors: 
- Topics where experience indicated that student comprehension was lower based upon course assessment tools and student feedback, and

- Topics where exemplar experiential activities were available from other engineering institutions and from the business management, philosophy, or law school curricula.

In addition we wanted to ensure that each identified experiential learning activity provided an opportunity for students to:

- Work within a team-based environment

- Gain practical experience as a team leader with sufficient opportunities for each student to prepare for, implement, and debrief their team on the extended experiential learning activity

- Be measured against objective performance standards for each activity

- Give and receive specific, meaningful, accurate, respectful and timely feedback from team members, teaching assistants, and instructors.

Beginning in the Fall 2013 semester, experiential leadership labs were incorporated into the Foundations of Global Leadership course within three of the five sections taught. Labs were developed based upon the criteria mentioned above with a specific focus of providing hands-on leadership experiences for students where the focus was on skill development while providing an opportunity for student leaders to receive real and timely feedback. Leadership labs covered the following topics:

- Rapid Fire Leader Experiences - Designed to provide each student an early opportunity to lead their team and receive preliminary feedback on their leadership skills. The secondary purpose is to encourage early progression of each team through the "forming" stage of team development, and especially to provide trust-building experiences for each team. A final purpose of the laboratory is to help team members gain practical experience providing and receiving effective feedback.

- Understanding Personality Differences - Designed to provide an introductory understanding of how personality differences affect interpersonal relationships.

- Problem Solving and Time Management - Designed to provide an opportunity for student teams to work together under time constraints to solve a problem in a competition setting drawing from engineering and leadership principles.

- Ethics Case Studies - To provide exposure and experience with case analysis in ethical decision-making with a focus on:

- Evaluating competing ethical positions

- Applying accepted ethical principles to particular circumstances

- Articulating alternative courses of action

- Developing acceptable compromises 
- Individual versus Team Effectiveness - Utilizing a survival scenario exercise (e.g. "Lost at Sea") this lab is designed for team building to bring a group together as they problem solve, make decisions, work as a team, communicate and learn to trust one another. Illustrates the positive elements when teams can work effectively together in making decisions.

- Understanding the World and Global Issues - To provide a team-based activity that provides an opportunity to conduct research, learn, prepare and effectively present persuasive information on a global issue.

- Appreciating and Understanding other Cultures - This exercise provides students an opportunity to (1) experience first hand cultural differences in communication styles, (2) the impact of these differences on the ability to engage in international business and (3) learn effective adaptation strategies (hence developing cross-cultural competencies.

- Global Case Studies - To provide exposure and a culminating experience in analyzing global case studies and presenting a professional analysis and position statement with persuasive and compelling information on the appropriate course of action.

A key element for successful experiential learning activities is to facilitate learning by doing. Students often struggle to provide effective feedback that is actionable. The "Team Leadership Assessment" form (Figure 3) was developed to provide students practical experience in giving and receiving feedback. The form helps students provide effective feedback that is specific, meaningful, accurate, respectful and timely (SMART). Each student completed a feedback form for the designated student leader for each lab. The designated team leader reviewed the feedback that included general comments and specific feedback on things they should Stop, Start, and Continue doing and then wrote a leadership reflection paper.

Leadership development is an evolutionary process that we continue to pursue in hopes of maximizing engineering student learning at Brigham Young University. The implementation of Leadership Labs within our Foundations of Global Leadership course has been well received as indicated by a few of the student comments from the Fall 2013 semester:

- Keep the leadership labs, they are a good way to involve students in the learning process and help students understand the concepts with the hands-on activities.

- The course was well thought out in such a way that allowed each student who chose to actively participate to develop many beneficial leadership skills. I learned a variety of new concepts and enjoyed every minute of the class. The leadership labs were spot on for giving students opportunities to practice what was taught in class. The labs were effective and enjoyable.

- All of the lectures and labs were fairly interactive and were great learning experiences.

- I love the leadership labs. They provide a great opportunity to apply the skills learned in class. I would say do more of them, and less lectures. But honestly the leadership labs are a genius idea I think. I hear a lot from other students, who don't like this class from other teachers, but I have rather enjoyed it and I think it is because of the labs.

- I felt the best part of this class were the leadership labs. They gave us the best opportunities to act as leaders in small group settings and receive immediate feedback. 
While many of the comments were very positive, many students commented that they wish they had more time in labs to debrief and discuss. As a result, it is our plans to increase the duration of each lab to provide a more enriching experience for each student.

The transition to experiential learning requires significant time and effort but the positive benefits of improved student cognitive learning together with a more enjoyable student interactive experience for instructors makes the efforts worthwhile.

Use this form to provide feedback for your team leader:

Summary of observation: Summarize the most significant observed leadership behaviors. Use sufficient detail to support an overall assessment of performance recorded at the bottom of the page.

Feedback: Provide 1-2 recommendations that the leader should stop doing, start doing, and continue doing. Make sure your feedback is SMART feedback (Specific, Meaningful, Accurate, Respectful, Timely)

\begin{tabular}{|l|l|l|l|}
\hline Stop & \\
\hline Continue & & \\
\hline \\
\hline
\end{tabular}

Figure 3 - Team Leader Assessment Form 


\section{Challenges and Benefits of Transition}

Many concerns about implementing experiential leadership education into engineering programs have to do with credit hours. An effective approach to demonstrate to students the value and importance of leadership is to integrate leadership education into required engineering courses. According to Amadin et al., this approach is less popular because of the "inflexible engineering curricula and additional course requirements ${ }^{15}$." An alternative approach is to create a supplementary program. This solution also has challenges because it will no longer reach all students, and still adds credit hours to an already strenuous major ${ }^{15}$.

In addition to credit hour challenges, transition to experiential education can be difficult for faculty. Extra effort is required to create labs, new courses, and change lecturing style. This can be a burden to busy faculty members ${ }^{4,25}$.

Although many leadership topics could benefit, experiential learning often takes significantly more in-class time to implement than lecture coverage of the same material. Thus, the instructor is faced with the challenge of "coverage" versus "depth" in selecting both the frequency and the duration of experiential learning activities. We adopted a balanced approach (7-8 experiential leadership labs over the course of the semester) at Brigham Young University in the hope that active engagement in selected activities would increase motivation and engagement in the class as a whole.

Although there are clear advantages to experiential learning, student perception of these activities may be mixed. Despite the substantial time investment in creating meaningful experiential learning activities, students perceive that they are "doing the work themselves", and give less credit to the instructor for facilitating the learning process. Thus student course evaluations may actually drop, despite an objective increase in measured student learning and retention.

Although there can be difficult challenges to overcome in transitioning to experiential leadership education, there are also many benefits of transitioning.

- Students learn more ${ }^{20}$

- Increase in self-directed learning ${ }^{26}$

- Increase in life-long learning readiness ${ }^{26}$

- $75 \%$ of information learned through experience is retained whereas only $5 \%$ of lecturebased learning is retained. In order to accomplish this, students must be given tools by exemplary leaders and provided opportunities to practice and use them ${ }^{12}$.

\section{Conclusion}

Research indicates that experiential learning is a more effective method for higher cognitive skill development. Our own experience coupled with the efforts and experiences of other wellrespected engineering institutions provide validity to the importance of incorporating experiential learning as an important method for leadership development in engineering students. Although challenges exist in the time and effort required to transition courses to an experiential learning 
approach it is apparent that leadership development is best accomplished through these means. In summary an effective approach to develop these leadership competencies are as follows:

1. Leadership education should be implemented early on in an academic career

2. Leadership education should be done in teams

3. Active involvement of students allows them to take responsibility for their own learning and the learning of others

4. Emphasis should be placed on skill building instead of knowledge acquisition

5. Gradually withdraw support, as students are more comfortable

6. Debriefing is the most critical part of experiential learning

We are eager to collaborate with other universities to learn and to share experiences as it applies to maximizing engineering student outcomes for leadership development.

\section{Bibliography}

\footnotetext{
${ }^{1}$ ABET. General Criterion 3. Student Outcomes. Criteria for Accrediting Engineering Programs, 2012-2013.

Accessed 1/3/2014 from http://www.abet.org/DisplayTemplates/DocsHandbook.aspx?id=3143

${ }^{2}$ Shuman, L. J., Besterfield-Sacre, M., \& McGourty, J. (2005). The ABET "Professional

Skills" - Can they be taught? Can they be assessed? Journal of Engineering

Education, 94 (1), 41-55.

${ }^{3}$ Russel, J.S., and J.T.P. Yao, "Education Conference Delivers Initiatives," Journal of Management in Engineering, ASCE, vol. 12, no. 6, pp. 17-26, 1996.

${ }^{4}$ Yadav, A., Subedi, D., Lundberg, M.A. and Buntin, C.F., "Problem-based Learning: Influence on Students'

Learning in an Electrical Engineering Course," Journal of Engineering Education, vol. 100, no. 2, pp. 253-280, 2011.

${ }^{5}$ Mcall, M., "Leadership Development through Experience," The Academy of Management Exectuive, vol. 18, no. 3, pp. 127-130, 2004.

${ }^{6}$ Seat, E., Parsons, J.R., and Poppen, W.A., "Enabling engineering performance skills: A program to teach communication leadership and teamwork," Journal of Engineering Education, vol. 90, pp. 7-15, 2001.

${ }^{7}$ Hinkle, G.C. What every engineer needs to know about leadership and management. SPIE Student Services and SPIE Professional Leadership Searies. Accessed 1/2/2014 from http://spie.org/x15555.xml.

${ }^{8}$ Farr, J.V., and Brazil, D.M., "Leadership Skills Development for Engineers", Engineering Management Journal, vol. 21, no. 1, pp. 3-8, 2009.

9 Tomek, S., "Developing a Multicultural, Cross-Generational, and Multidisciplinary Team: An Introduction for Civil Engineers," Leadership Education for Engineering Students, vol. 11, no. 2, pp. 191-196, 2011.

${ }^{10}$ Bloom, B.S., Engelhart, M.D., Furst, E.J., Hill, W.H., Krathwoh, D.R., "Taxonomy of Educational Objectives: the Classification of Educational Goals," Handbook I: Cognitive Domain, New York, Longmans, Green and Co., 1956.

${ }^{11}$ Kolb, D., Experiential Learning: Experience as the source of learning and development, New Jersey: Prentice Hall, 1984.

${ }^{12}$ Fulford, M., "Practice What You Preach: using an Experiential Learning Approach to Teach," Journal of Leadership, Accountability, and Ethics, vol. 10, no. 2, pp. 81-86, 2013.

${ }^{13}$ Prince, M.J., and Felder, R.M., "Inductive Teaching and Learning Methods: Definitions, Comparisons, and Research Bases," Journal of Engineering Education, pp. 123-138, 2006.

${ }^{14}$ Wurdinger, S. D., \& Carlson, J. A. (2010). Teaching for experiential learning: Five approaches that work. Lanham, MD: Rowman \& Littlefield Education.).

${ }^{15}$ Osagiede, A., Cox, M.F. and Ahn, B., "Purdue University's Engineering Leadership Program: Addressing the Short-fall of Engineering Leadership Education," in ASEE Annual Conference \& Exposition, 2013.

${ }^{16}$ Scarborough, J.D., "Project Management: A Critical Area of Study for Engineering \& Engineering Technology Students," in ASEE Annual Conference, 1998.
} 
${ }^{17}$ Kolb, A.Y. and Kolb, D.A., "Learning Styles and learning Spaces: Enhancing Experiential Learning in Higher Education," Academy of Managment Learning \& Education, vol. 4, no. 2, pp. 193-212, 2005.

${ }^{18} \mathrm{Ng}$, K., Van Dyne, L. and Ang, S., "From Experience to Experiential Learning: Cultural Intelligence as a Learning Capability for Global Leader Development," Academy of Management Learning \& Education, vol. 8, no. 4, pp. 511526, 2009.

${ }^{19}$ Hunter, K.W. and Matson, J.O., "Engineering Leadership and Teamwork Development Through Experiential Learning," in ASEE Annual Conference and Exposition, 2001.

${ }^{20}$ Bangs, J., "Experiential learning In An Organizational Leadership Program," Journal of College Teaching \& Learning, vol. 8, no. 10, pp. 29-34, 2011.

${ }^{21}$ Guthrie, K.L. and Jones, T.B., "Teaching Learning: using Experiential Learning and Reflection for Leadership Education," New Directions For Student Services, no. 140, 2012.

${ }^{22}$ GEL Program. Gordon-MIT Engineering Leadership Program. Accessed 1/3/2014 from http://web.mit.edu/gordonelp/

${ }^{23}$ RCEL 4 Year Certificate Program. Program requirements for Rice Center for Engineering Leadership Four Year Certificate Program. Accessed 1/3/2014 from http://rcel.rice.edu/requirements

${ }^{24}$ Engineering Leadership Development Minor. Penn State University Academics. Accessed 1/3/2014 from http://www.sedtapp.psu.edu/leadership/academics.php

${ }^{25}$ Suckarieh, G. and Krupar, J., "Leadership and Teamwork Education for Engineering and Technology Students: An Experiential Learning and Community Service Approach," in ASEE Annual Conference \& Exposition, 2005.

${ }^{26}$ Jiusto, S. and DiBiasio, D., "Experiential learning Environments: Do They Prepare Our Students to be SelfDirected, Life-Long Learners?," Journal of Engineering Education, vol. 95, no. 3, pp. 195-204, 2006. 